\title{
A Pentiptycene-Derived Light-Driven Molecular Brake
}

\author{
Jye-Shane Yang, ${ }^{*,}{ }^{\dagger}$ Yao-Ting Huang, ${ }^{\dagger}$ Jinn-Hsuan Ho, ${ }^{\dagger}$ Wei-Ting Sun, ${ }^{\dagger}$ \\ Hsin-Hau Huang, ${ }^{\dagger}$ Ying-Chih Lin, ${ }^{*, \dagger}$ Shing-Jong Huang, ${ }^{\dagger}$ Shou-Ling Huang, ${ }^{\dagger}$ \\ Hsiu-Feng Lu, ${ }^{\ddagger}$ and Ito Chao*,‡
}

Department of Chemistry and Instrumentation Center, National Taiwan University, Taipei, Taiwan 10617, and Institute of Chemistry, Academia Sinica, Taipei,

Taiwan 11529

jsyang@ntu.edu.tw; yclin@ntu.edu.tw; ichao@chem.sinica.edu.tw

Received March 26, 2008

\section{ABSTRACT}

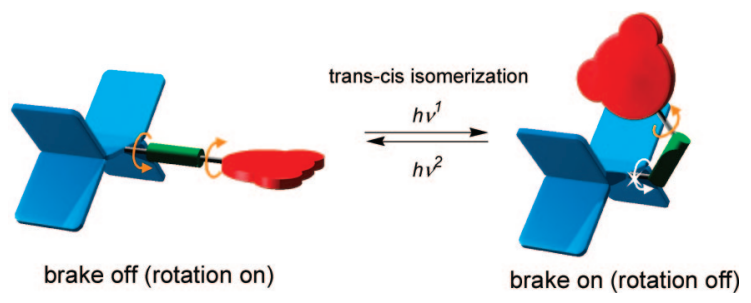

A room-temperature light-driven molecular brake (1), consisting of a pentiptycene rotator, a 3,5-dinitrophenyl brake, and a photoisomerizable ethenyl spacer, is reported. The rotation rates of the rotator differ by about 9 orders of magnitude between the brake-on (cis-1) and brake-off (trans-1) states.

The ability to control specific motions of subunits in molecules or supramolecular ensembles is essential for the development of molecular machines. ${ }^{1}$ As photons are cleaner, faster, and longer-range control elements (stimuli) compared to chemicals and electrons, ${ }^{2}$ many efforts have been devoted to constructing prototypes of light-driven or photocontrollable linear and rotary motions. ${ }^{1-3}$ However, the progress in some aspects falls behind the corresponding chemical-controlled systems. One particular example is "molecular brakes", in which the Brownian rotary motion of a rigid wheel component about a single bond can be slowed down by a brake unit. Since the first chemical-driven molecular brake reported

\footnotetext{
† National Taiwan University.

Academia Sinica.

(1) Balzani, V.; Venturi, M.; Credi, A. Molecular Devices and Machines-A Journey into the Nano World; Wiley-VCH: Weinheim, 2003.

(2) (a) Raymo, F. M. Angew. Chem., Int. Ed. 2006, 45, 5249-5251. (b) Credi, A. Aust. J. Chem. 2006, 59, 157-169. (c) Saha, S.; Stoddart, J. F. Chem. Soc. Rev. 2007, 36, 77-92.

(3) (a) Kottas, G. S.; Clarke, L. I.; Horinek, D.; Michl, J. Chem. Rev. 2005, 105, 1281-1376. (b) Kay, E. R.; Leigh, D. A.; Zerbetto, F. Angew. Chem., Int. Ed. 2007, 46, 72-191. (c) Feringa, B. L. J. Org. Chem. 2007,
} $72,6635-6652$. by Kelly and co-workers in $1994,{ }^{4}$ several others have also been developed. ${ }^{5}$ The first approach toward a light-driven counterpart was reported by Feringa and co-workers in 1997 using a cis-trans interconvertable sterically overcrowded alkene. ${ }^{6}$ However, the desired rotary motion is restricted for both the trans and cis isomers at room temperature because of unexpectedly high and similar rotational barriers (19.7 and $19.0 \mathrm{kcal} \mathrm{mol}^{-1}$, respectively, at $\left.303 \mathrm{~K}\right)$. In a later report on a similar system, the rate of rotation $\left(k_{\mathrm{rot}}\right)$ was determined to be less than $0.1 \mathrm{~s}^{-1}$ for all the stable and unstable states at 298 K. ${ }^{7}$ To date, an effective room-temperature photocontrollable molecular brake has yet to be demonstrated.

(4) Kelly, T. R.; Bowyer, M. C.; Bhaskar, K. V.; Bebbington, D.; Garcia, A.; Lang, F.; Kim, M. H.; Jette, M. P. J. Am. Chem. Soc. 1994, 116, 36573658 .

(5) (a) Jog, P. V.; Brown, R. E.; Bates, D. K. J. Org. Chem. 2003, 68, 8240-8243. (b) Annunziata, R.; Benaglia, M.; Cinquini, M.; Raimondi, L.; Cozzi, F. J. Phys. Org. Chem. 2004, 17, 749-751. (c) Alfonso, I.; Burguete, M. I.; Luis, S. V. J. Org. Chem. 2006, 71, 2242-2250.

(6) Schoevaars, A. M.; Kruizinga, W.; Zijlstra, R. W. J.; Veldman, N.; Spek, A. L.; Feringa, B. L. J. Org. Chem. 1997, 62, 4943-4948.

(7) ter Wiel, M. K. J.; van Delden, R. A.; Meetsma, A.; Feringa, B. L. Org. Biomol. Chem. 2005, 3, 4071-4076. 
We report herein the first example of a room-temperature light-driven molecular brake (1) that displays distinct rates of rotation in the brake-on versus brake-off states. The rigid pentiptycene group ${ }^{8}$ in $\mathbf{1}$ serves as a four-bladed wheel, and the trans-cis photoisomerizable dinitrostyryl group behaves as a photoresponsive brake component (Figure 1). In the trans

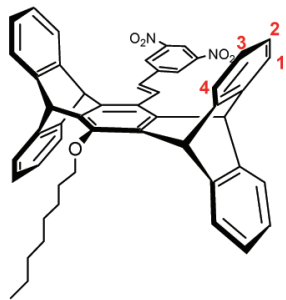

trans-1
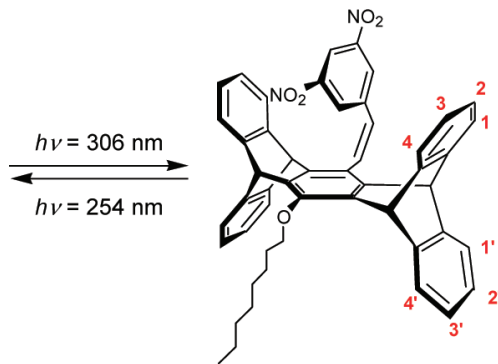

cis-1
Figure 1. Molecular structures of a light-driven molecular brake (1) corresponding to the schematic illustrations shown in the Abstract graphic. The trans (trans-1) and cis (cis-1) isomers correspond to the brake-off and brake-on states. The numerical labels for protons and carbons are for discussion of the VT NMR spectra.

form (trans $\mathbf{- 1}$, the brake-off state), the pentiptycene rotator undergoes free rotation $\left(k_{\mathrm{rot}} \approx 10^{9} \mathrm{~s}^{-1}\right)$ due to a small rotational barrier $\left(\Delta G^{\ddagger} \approx 4.5 \mathrm{kcal} / \mathrm{mol}\right.$ at $\left.298 \mathrm{~K}\right)$. However, such a rotation is nearly blocked $\left(k_{\text {rot }}=3 \mathrm{~s}^{-1}, \Delta G^{\ddagger} \approx 16.4\right.$ $\mathrm{kcal} \mathrm{mol}^{-1}$ at $298 \mathrm{~K}$ ) in the cis form (cis-1, the brake-on state) as the result of an intercalation of the dinitrophenyl group into the U-shaped cavities of the rotator. As a result, the rate of rotation in the brake-on and brake-off states differs by nearly 9 orders of magnitude at $298 \mathrm{~K}$.

The synthesis of molecular brake $\mathbf{1}$ is outlined in Scheme 1. The commercially available 3,5-dinitrobenzyl alcohol 2

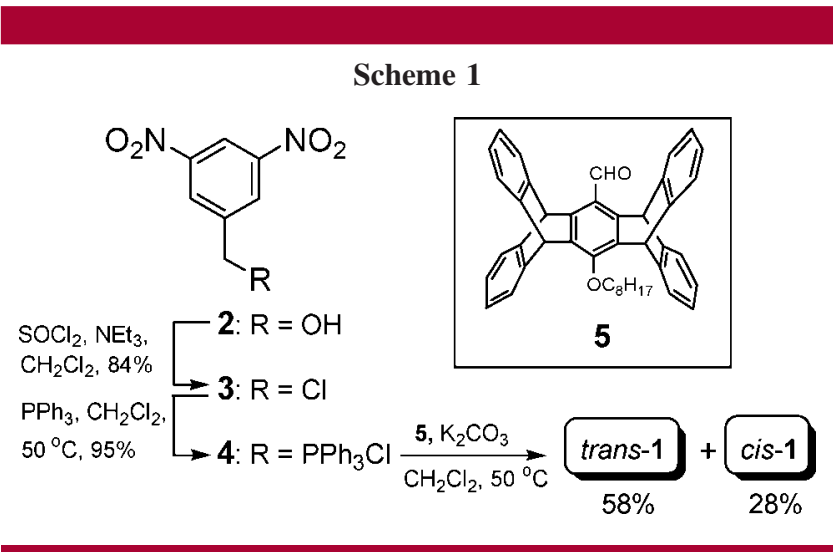

was first converted with thionyl chloride to 3,5-dinitrobenzyl chloride $\mathbf{3}$, which then reacted with triphenylphosphine to form the phosphonium salt 4 . The latter reaction was kept

(8) For a recent review on pentiptycene chemistry, see: Yang, J.-S.; Yan, J.-L. Chem. Commun. 2008, 1501-1512. under $60{ }^{\circ} \mathrm{C}$, because the salt decomposes at higher temperatures. The stilbene backbone was finally constructed by the Wittig reaction of $\mathbf{4}$ and formylpentiptycene $\mathbf{5}$, the synthesis of which has recently been reported. ${ }^{9}$ The resulting trans and cis isomers of $\mathbf{1}(2: 1)$ can be readily separated by column chromatography.

Figure 2 shows the aromatic region of ${ }^{1} \mathrm{H}$ and ${ }^{13} \mathrm{C}$ NMR spectra of trans-1 and cis-1 in DMSO- $d_{6}$ at $298 \mathrm{~K}$. The

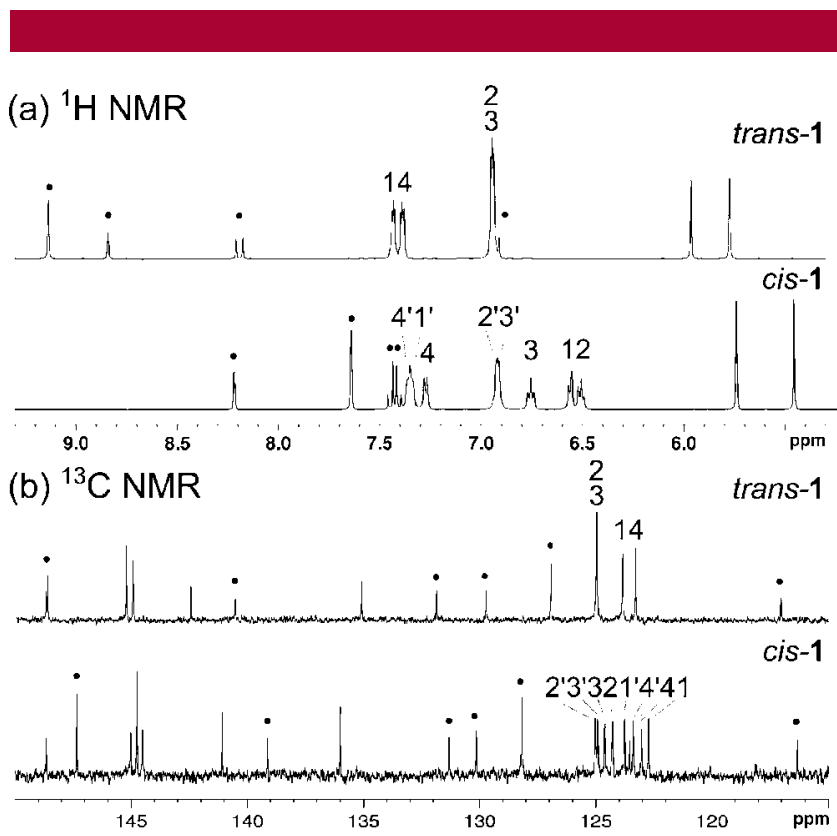

Figure 2. Aromatic region of (a) ${ }^{1} \mathrm{H}$ and (b) ${ }^{13} \mathrm{C}$ NMR spectra of trans-1 and cis-1 in DMSO- $d_{6}$ at $298 \mathrm{~K}$. The solid circles denote peaks due to the dinitrostyryl group and the Arabic numerals denote the corresponding protons and carbons labeled in Figure 1.

presence of only one set of signals for trans-1 suggests that both the pentiptycene rotator and the dinitrophenyl brake can undergo free rotation about the $\mathrm{C}_{\text {vinyl }}-\mathrm{C}_{\text {aryl }}$ single bonds. In contrast, the observation of two sets of signals for the pentiptycene methine nuclei but not for the dinitrophenyl nuclei indicates that rotation of the rotator but not the brake component is slower than the NMR time scale. Except for some quaternary carbons, the signals can be unambiguously assigned on the basis of a series of 2D NMR experiments, including COSY, HSQC, NOESY, and ROESY (Supporting Information, Figures S5-S11), and the numerical labels in Figure 2 correspond to the labeled protons and carbons in Figure 1.

The information about rotational barriers and rates for the pentiptycene rotator in cis-1 can be obtained from variabletemperature (VT) NMR studies and spectral simulations. As shown in Figure 3a, some of the proton peaks at $298 \mathrm{~K}$ coalesce at higher temperatures. For example, a coalescence temperature $\left(T_{\mathrm{c}}\right)$ near $348 \mathrm{~K}$ is found for protons $\mathrm{H}_{3}$ and $\mathrm{H}_{3^{\prime}}$, corresponding to an energy barrier of $\Delta G^{\ddagger}(348 \mathrm{~K})=16.9$ $\pm 0.2 \mathrm{kcal} \mathrm{mol}^{-1}$. However, the multiplicity of proton signals and the presence of more than one type of spin systems in

(9) Yang, J.-S.; Ko, C.-W. J. Org. Chem. 2006, 71, 844-847. 
(a) ${ }^{1} \mathrm{H}$ NMR

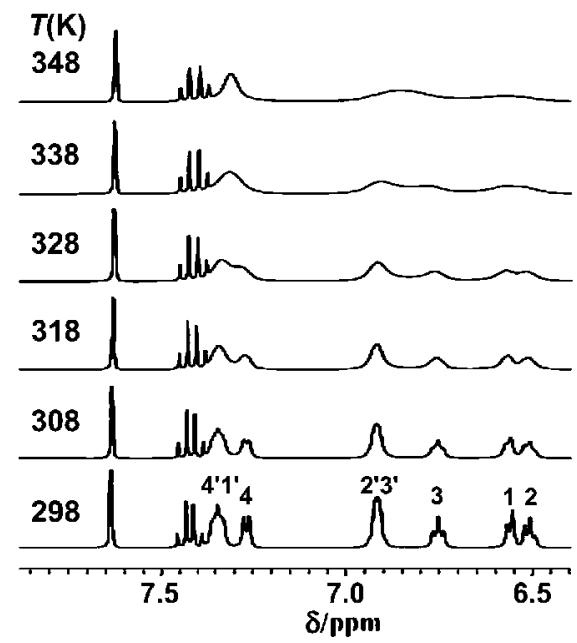

(b) ${ }^{13}$ C NMR

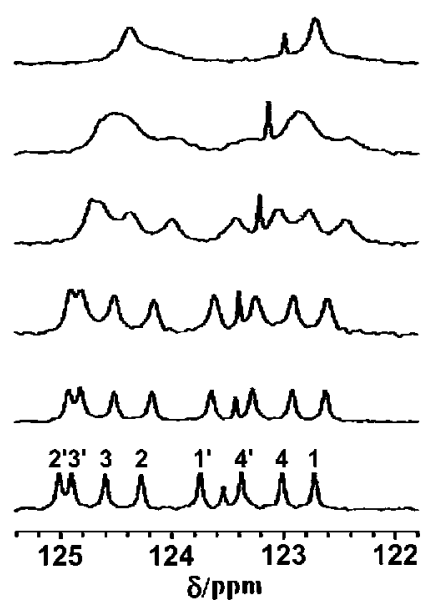

(c) Simulated ${ }^{13} \mathrm{C}$ NMR

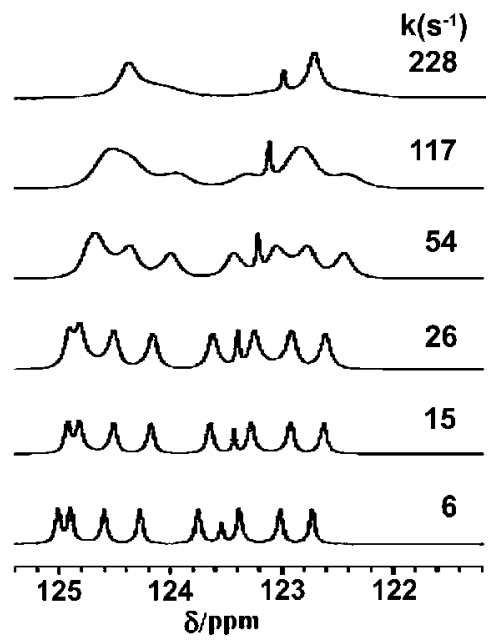

Figure 3. Pentiptycene peripheral phenylene (blade) region of the (a) experimental proton and (b) carbon and (c) simulated carbon VT NMR spectra of cis-1 ( 9 and $60 \mathrm{mM}$ for proton and carbon, respectively, DMSO- $d_{6}, 500 \mathrm{MHz}$ ). Values of temperature $(T$, K) and interconversion rate $\left(k, \mathrm{~s}^{-1}\right)$ between the two isoenergetic states are also given for every trace. Simulated spectra were obtained with the Topspin 2.0 program. $^{10}$

the phenylene blades of the pentiptycene rotator prevent a direct spectral simulation. Thus, a VT ${ }^{13} \mathrm{C}$ NMR experiment was carried out, and the resulting spectra (Figure $3 b$ ) were simulated (Figure 3c). ${ }^{10}$ The results suggest that the rotation is nearly blocked at $298 \mathrm{~K}$, and the rate constant $(k)$ for interconversion between the two isoenergetic conformers of cis-1 is only $6 \mathrm{~s}^{-1}$. In other words, it takes ca. $0.33 \mathrm{~s}$ for a $360^{\circ}$ rotation (i.e., $\left.k_{\mathrm{rot}}=k / 2\right)$. The activation energy $\left(E_{\mathrm{a}}=\right.$ $\left.14.8 \pm 0.5 \mathrm{kcal} \mathrm{mol}^{-1}\right)$ and enthalpic $\left(\Delta H^{\ddagger}=14.1 \pm 0.5\right.$ $\left.\mathrm{kcal} \mathrm{mol}{ }^{-1}\right)$ and entropic $\left(\Delta S^{\ddagger}=-7.6 \pm 1.4 \mathrm{cal} \mathrm{K}^{-1} \mathrm{~mol}^{-1}\right)$ contributions to the free energy of activation $\left(\Delta G^{\ddagger}=16.4\right.$ and $16.8 \mathrm{kcal} \mathrm{mol}^{-1}$ at 298 and $348 \mathrm{~K}$, respectively) were obtained by Arrhenius and Eyring plots (Supporting Information, Figures S12 and S13). Since the rotational barrier is mainly due to an enthalpic factor, the transition state is destabilized mainly due to steric effect. It should also be noted that the values of $\Delta G^{\ddagger}$ at $348 \mathrm{~K}$ deduced from ${ }^{1} \mathrm{H}$ and ${ }^{13} \mathrm{C}$ VT NMR are essentially the same.

To obtain structural information about the transition structure and the optimized conformation of cis-1 along the pentiptycene rotation coordinates, we have carried out DFT (BMK/6-311+G**//B3LYP/6-31G*) calculations. ${ }^{11}$ The calculation results are justified by the good agreement of the calculated $\left(16.75 \mathrm{kcal} \mathrm{mol}^{-1}\right)$ and the NMR-determined $\Delta G^{\ddagger}$ value $\left(16.4 \mathrm{kcal} \mathrm{mol}^{-1}\right)$ at $298 \mathrm{~K}$. The brake moiety in the structurally optimized cis-1 (Figure 4a) is, as expected, located at the U-shaped cavities, although the protruding pentiptycene blades create two types of cavities (U- vs $\mathrm{V}$-shaped). The $\mathrm{V}$-shaped cavities are in fact inaccessible to

(10) All line shape simulations were performed using the Bruker Topspin 2.0 program.

(11) To expedite the calculations, the octyl group was replaced by a methyl group. The BMK functional has been shown to be a good functional in terms of thermochemistry and kinetics for main-group elements. Zhao, Y.; Truhlar, D. G. Acc. Chem. Res. 2008, 41, 157-167. the dinitrophenyl group as a result of severe steric interactions with $\mathrm{H}_{1}, \mathrm{H}_{1^{\prime}}$, and the bridgehead hydrogen atom, as revealed by the transition structure (Figure $4 b$ ). Strains in bond angles

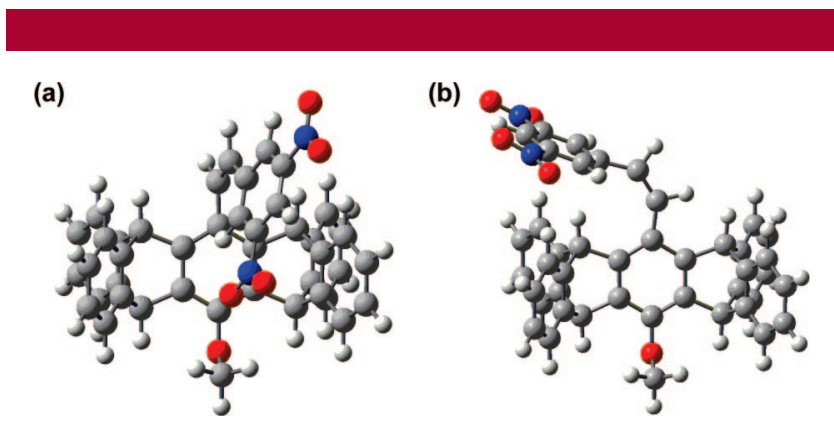

Figure 4. DFT-derived structures for cis-1: (a) the optimized conformation and (b) the transition structure along the pentiptycene rotation coordinate.

and bond lengths also account in part for the high energy of the transition state. The structural coordinates are supplied as Supporting Information.

An attempt to evaluate the rotational barriers for the pentiptycene rotator in trans-1 and the dinitrophenyl brake in cis-1 with VT ${ }^{1} \mathrm{H}$ NMR was hampered by their low energy barriers, as we could not observe decoalescence of the signals even at a temperature as low as $183 \mathrm{~K}$ (in $\mathrm{CD}_{2} \mathrm{Cl}_{2}$ ). In view of the good agreement of DFT calculations and NMR experiments in the pentiptycene rotation barrier of cis-1, DFT calculations have been applied to retrieve the corresponding information for that in trans-1 $\left(4.45 \mathrm{kcal} \mathrm{mol}^{-1}\right)^{12}$ and the brake rotation in cis-1 $\left(6.85 \mathrm{kcal} \mathrm{mol}^{-1}\right)$. With a calculated $\Delta G^{\ddagger}$ value differing by $12.3 \mathrm{kcal} \mathrm{mol}^{-1}$ for the pentiptycene 
rotation in trans-1 versus cis-1 at $298 \mathrm{~K}$, the difference in rotation rate is in the order of $10^{9} .{ }^{13}$

Photoswitching between trans-1 and cis-1 has been investigated in dichloromethane solutions. ${ }^{14,15}$ On the basis of their relative molar absorptivity $(\varepsilon)$, the wavelengths of $306\left(\varepsilon_{\text {trans }-1} / \varepsilon_{\text {cis }-1}=3.35\right)$ and $254 \mathrm{~nm}\left(\varepsilon_{\text {trans }-1} / \varepsilon_{\text {cis }-1}=1.20\right)$ were adopted for the trans- $\mathbf{1} \rightarrow$ cis $\mathbf{- 1}$ and the cis-1 $\rightarrow$ trans $-\mathbf{1}$ conversion, respectively. The corresponding ratio of [trans1]/[cis-1] determined by ${ }^{1} \mathrm{H}$ NMR is $25 / 75$ and $45 / 55$ in the photostationary states. As monitored by absorption spectra (Figure 5), photoswitching between the two photostationary states is quite robust (Figure 5, inset).

In summary, the pentiptycene-derived stilbene $\mathbf{1}$ has been prepared and investigated as a photocontrollable molecular brake that functions at room temperature. Both experimental and computational results reveal that at $298 \mathrm{~K}$ rotation of the four-bladed pentiptycene (the rotator) is "free" in trans-1 but is nearly blocked in cis-1. The brake-on (cis-1) and brakeoff (trans-1) states differ by a rotation rate of $\sim 10^{9}$-fold and can be interconverted through the ethylene trans-cis photoisomerization reactions. Studies on the related systems are in progress in our laboratory in order to gain insights into substituent effects on the brake performance.

(12) A barrier of $\sim 1000 \mathrm{~cm}^{-1}\left(2.86 \mathrm{kcal} \mathrm{mol}^{-1}\right)$ was found for the rotation of a single phenyl ring in trans-stilbene and its 4,4'-disubstituted derivatives. Arp, Z.; Chiang, W.-Y.; Laane, J.; Sakamoto, A.; Tasumi, M. J. Phys. Chem. A 2002, 106, 3479-3484.

(13) Even with a consideration of $1-2 \mathrm{kcal} / \mathrm{mol}$ uncertainty in calculated $\Delta G^{\ddagger}$ value for pentiptycene rotation in trans-1, the ratio of the on-off rotation rate is still around $10^{7}-10^{8}$

(14) The quantum yields for the trans-1 $\rightarrow$ cis-1 and cis-1 $\rightarrow$ trans-1 photoisomerization in dichloromethane are 0.17 and 0.21 , respectively.

(15) Thermal isomerization of the double bond in $\mathbf{1}$ has been evaluated by DFT (UBMK/6-311+G**//UB3LYP/6-31G*) modeling. The calculated free energy barrier was $45.22 \mathrm{kcal} \mathrm{mol}^{-1}$ relative to cis-1, and the free energy difference between cis-1 and trans-1 was $0.76 \mathrm{kcal} \mathrm{mol}^{-1}$. These values are similar to the computational and experimental data reported for the parent stilbene $\left(41-46 \mathrm{kcal} \mathrm{mol}^{-1}\right.$ for the thermal isomerization barrier and $2.3-5.7 \mathrm{kcal} \mathrm{mol}^{-1}$ for the energy difference between the cis and trans isomers), see: (a) Meier, H. Angew. Chem., Int. Ed. 1992, 31, 1399-1420. (b) Han, W.-G.; Lovell, T.; Liu, T.; Noodleman, L. ChemPhysChem 2002, 3, $167-178$.

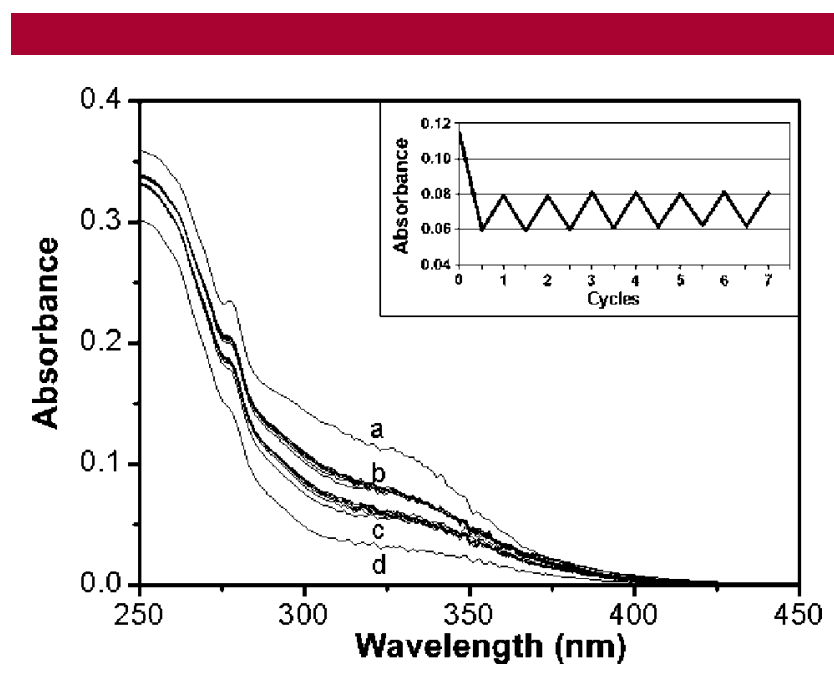

Figure 5. Absorption spectra of trans-1 (curve a) and cis-1 (curve d) and their photostationary states irradiated with alternating 306(curves c) and 254-nm (curves b) UV light irradiation in dichloromethane. Inset shows the changes in absorbance at $322 \mathrm{~nm}$ starting from trans $\mathbf{- 1}(10 \mu \mathrm{M})$ for 7 switching cycles.

Acknowledgment. Financial support for this work was provided by the National Science Council, Academia Sinica, and National Taiwan University. The computing time granted by the National Center for High-Performance Computing and the Computing Center of Academia Sinica is acknowledged. We also thank Mr. G.-J. Huang for measuring the photoisomerization quantum yields.

Supporting Information Available: Experimental methods, synthesis of intermediates 3 and 4, 1D and 2D NMR spectra and DFT-derived structural coordinates for trans-1 and cis-1, and the Arrhenius and Eyring plots for cis-1. This material is available free of charge via the Internet at http://pubs.acs.org.

OL800689A 